\title{
ACTIVITIES OF THE NATIONAL ACADEMY OF SCIENCES \\ IN RELATION TO THE RADIATION EFFECTS RESEARCH FOUNDATION
}

Progress Report

December 1, 1990 - May 31, 1991

Charles W. Edington

Board on Radiation Effects Research

National Research Council

Washington, D.C. 20418

June 1991

\author{
PREPARED FOR THE U.S. DEPARTMENT OF ENERGY \\ UNDER GRANT NUMBER DE-FG05-90ER60960
}

\section{DISCLAIMER}

This report was prepared as an account of work sponsored by an agency of the United States Government. Neither the United States Government nor any agency thereof, nor any of their employees, makes any warranty, express or implied, or assumes any legal liability or responsibility for the accuracy, completeness, or usefulness of any information, apparatus, product, or process disclosed, or represents that its use would not infringe privately owned rights. Reference herein to any specific commercial product, process, or service by trade name, trademark, manufacturer, or otherwise does not necessarily constitute or imply its endorsement, recommendation, or favoring by the United States Government or any agency thereof. The views and opinions of authors expressed herein do not necessarily state or reflect those of the United States Government or any agency thereof. 
PROGRESS REPORT

GRANT NO. DE-FG05-90ER60960

DECEMBER 1, 1990 - MAY 31, 1991

Although the time has been short, progress since 1 December 1990 on the various epidemiological, clinical, and laboratory research activities being conducted at RERF continues in a productive and satisfactory manner. These investigations continue to address the late health effects, both somatic and teratogenic, that may be induced by radiation in the survivors of the atomic bombs in Hiroshima and Nagasaki. In addition, research to determine the induction of genetic effects that might be transmitted to the children of exposed parents is progressing at a satisfactory pace.

Advances are continuing to be made in the collection and analysis of data on mortality that has occurred during the period 1950-1989 (up-dating the last analysis by five additional years) in the Life Span Study cohort. In addition, risk analyses of the incidence of solid tumors and cancers of the hematopoietic system, using tumor registry data, are in the final stages of completion, and three manuscripts are in preparation. They will include (1) a manuscript on methods which will describe the registry operations, present basic data on number of tumors, and the protocol for diagnostic confirmation of tumors; (2) a paper on radiation risk for solid tumors; and (3) a paper on radiation risk for hematopoietic cancers.

In the clinical research area, considerable work is continuing to ascertain whether diseases or other clinical entities are related to radiation exposure and specifically to determine if they increase with increasing radiation dose. This research is utilizing the extensive clinical records that have been obtained in the biennial physical examinations (now in the 16th cycle) of the Adult Health Study cohort, investigations are in progress to study the relationship, if any, of 22 non-cancer diseases with radiation exposure. Because of the potential involvement on other environmental, occupational, competing risks or primary medical cause, such as cancer, careful evaluation of the non-cancer disease observatiuns are in progress.

Extensive investigations on the children of survivors of the atomic bombs have been conducted over a period of 42 years. Although no increase in genetic effects have been observed to date in the children of exposed parents as compared to children of non-exposed parents, blood samples are routinely collected from exposed and non-exposed parents and their children so that studies of mutation 
at the DNA base level can be conducted when the appropriate molecular methodologies and/or technologies become available. At the present time, portions of blood samples from these families are being stored at liquid nitrogen temperatures. Lymphocytes are separated from the remaining portions of the samples and are transformed by the Epstein-Barr virus to an immortal state and allowed to proliferate to a predetermined level and then stored for future use. In addition to these studies, considerable work is continuing to develop and use chromosomal aberrations and somatic mutations as biological dosimeters and for relating acute radiation effects with estimated radiation dose. New methods for measuring both somatic mutations, using flow cytometry, and chromosome aberrations, using chromosome painting techniques, are in progress.

Molecular and cellular approaches are being used in very important investigations designed to determine whether the surviving population represents a biased sample of radiation resistant individuals which would favor exposed persons with a stronger immune response. In this connection, investigations on the radiation sensitivity of cells from survivors have been compared to the sensitivity of cells obtained from non-exposed individuals are being carried out. Results obtained in these experiments, indicate that there is no difference in the radiation sensitivity of the cells of the two populations. In addition, studies are in progress to determine whether immunological approaches in methodologies would enhance the investigation of radiation-induced mutation rates and tumor susceptibility of lymphoid and hematopoietic tissues. A number of sophisticated studies are being conducted to relate molecular changes in immunocompetent and genetic constitution of exposed individuals and cancer or other biological effects,

In addition to the research activities, an RERF Program Planning Committee was established, and it has met either in ad hoc or full meetings over the past eight months to consider the recommendations made by the four workshops which were held over the past three years. Although some of these recommendations are currently being addressed in the various departments at the Foundation, the Committee is in the process of developing a multiple year plan for future research activities at RERF. This plan will also consider personnel, facility, and fiscal needs to continue this unique and scientifically important research program.

In March, the eighteenth meeting of the RERF Scientific Council met in Hiroshima (25-27 March) at which time the various programs of RERF were presented. Every third year, the RERF Board of Directors holds it meeting in the United States. In June (19-21 June), the twenty-fifth meeting of the Board will be held at the Academy's Beckman Centor in Irvine, California.

A number of relevant recent publications as RERF technical reports, commentary and review articles, and publications in the open literature are enclosed as additional evidence of progress in this important research program. 
Since the tours of duty of the various NAS scientific and/or administrative personnel working at. RERF are, for the most part, two years in length, recruitment of individuals to replace them is a continuous process. Over the past year, the Academy has been successful in its responsibilities for recruitment of U.S. citizens to serve as directors of the Foundation and scientists to work at RERF. In this connection, Dr. James E. Trosko, Professor of Pediatrics and Human Development at Michigan State University has replaced Dr. Seymour Abrahamson as Chief of Research at RERF. Dr. Abrahamson has returned to his position at the University of Wisconsin. In addition, Dr. William J. Schull, Director and Ashbel Smith Professor, Center for Demographic and Population Genetics, Graduate School of Biomedical Sciences, University of Texas, has replaced Dr. Sidney Marks as a Permanent Director in residence at RERF. Two visiting directors, Dr. William W. Burr, Jr. and Dr. Warren K. Sinclair will complete their term in off ce in June 1991. Dr. Sinclair has been nominated to serve an additional term as a visiting director, and Mr. Seymour Jablon of the National Cancer Institute has been nominated to replace $\mathrm{Dr}$. Burr. In addition, two computer specialists have bean hired to work in the Research Information Center at RERF.

Intensive efforts are being made to attract qualified junior, as well as senior, epidemiologists to move to Japan and become involved in the increasingly important epidemiological studies. Although we have not had any acceptances at this time, we have at least three, perhaps four, epidemiologists who are definitely interested in the possibility of working at RERF. 


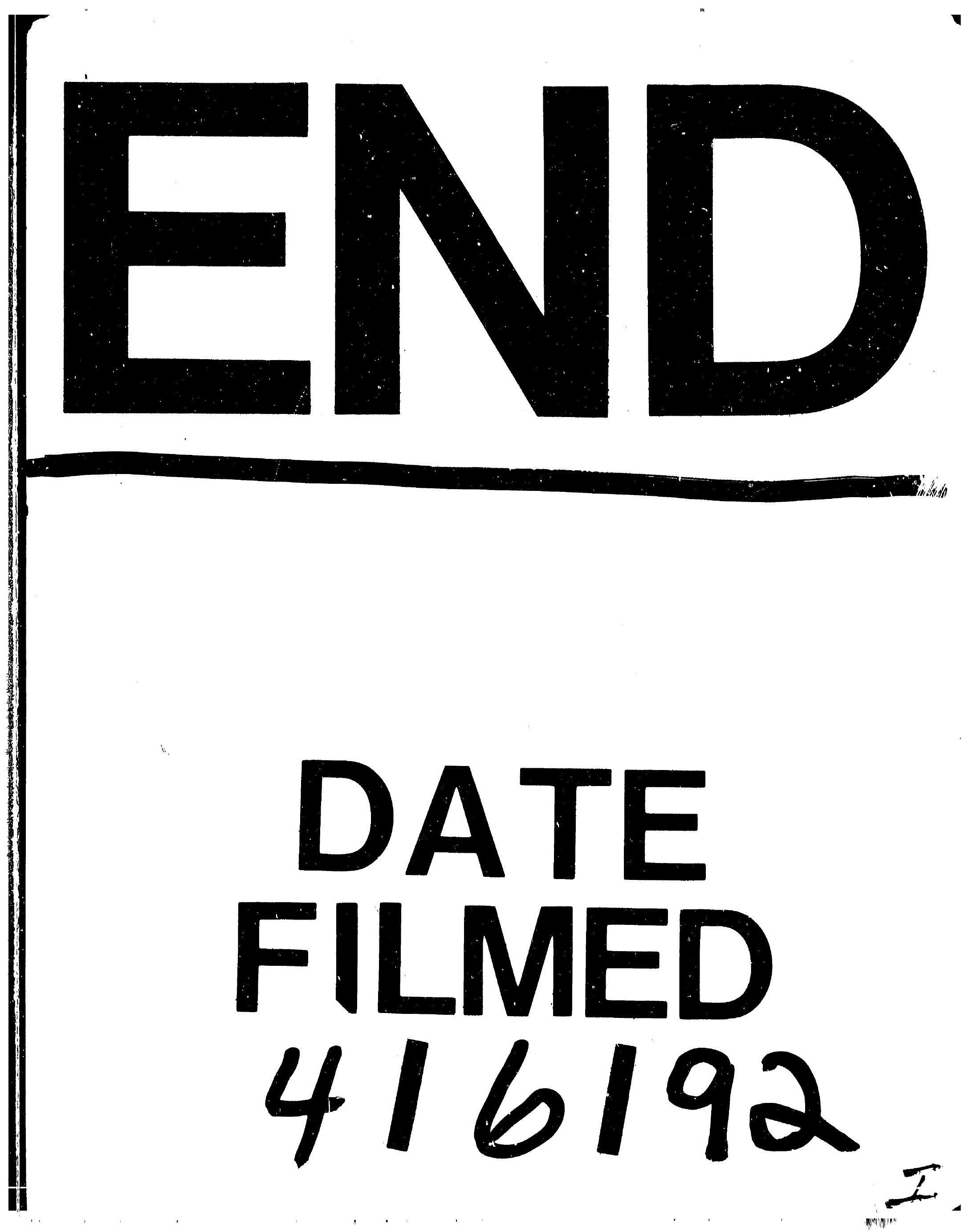


